\title{
Use of Subspace Identification Techniques for Solar Fields Mathematical Modeling
}

\author{
Ademar Gonçalves da Costa Junior$, Paulo Renato da Costa Mendes ${ }^{\S}$, Julio Elias Normey-Rico ${ }^{\S}$ \\ *Instituto Federal de Educação, Ciência e Tecnologia da Paraíba (IFPB), Laboratório de Instrumentação, Sistemas de \\ Controle e Automação (LINSCA), João Pessoa, PB, Brazil (e-mail: ademar.costa@ifpb.edu.br) \\ ${ }^{\S}$ Universidade Federal de Santa Catarina (UFSC), Grupo de Pesquisa em Energias Renováveis (GPER), Florianópolis, SC, \\ Brazil (e-mails: paulorcm@hotmail.com, julio.normey@ufsc.br)
}

\begin{abstract}
Concentrated solar fields (CSP) are used for the generation of electric energy through the conversion of thermal energy into electricity. Due to the complexity of the dynamical system behavior, identification techniques are an alternative to the use of mathematical models based on phenomenological equations. The use of subspace identification technique for the deterministic-stochastic case in this paper has proved to be interesting from the point of view of the prediction of the behavior of the output temperature of the solar field. Moreover, the linear time-invariant state-space model can be used in designing model-based controllers.
\end{abstract}

Resumo: Campos solares concentrados são utilizados para a geração de energia elétrica por meio da conversão de energia térmica em elétrica. Devido à complexidade do comportamento dinâmico destes processos, as técnicas de identificação são uma alternativa ao uso do modelamento matemático baseado em equações fenomenológicas. A utilização de uma técnica de identificação por subespaço para o caso determinístico-estocástico neste artigo mostrou-se ser interessante do ponto de vista da predição do comportamento da temperatura de saída do campo solar. Ainda, o modelo de espaço de estados linear invariante no tempo obtido pode ser empregado no projeto de controladores baseados em modelos.

Keywords: Concentrated solar power; solar energy; system identification; subspace identification; mathematical modeling; Acurex; Almeria Solar Platform.

Palavras-chaves: Campos solares concentrados; energia solar; identificação de sistemas; identificação por subespaços; modelamento matemático; Acurex; Plataforma solar de Almería.

\section{INTRODUCTION}

Solar energy is used for the generation of electricity through photovoltaic (PV) plants, and indirectly, by concentrated solar power (CSP) plants to produce steam used to drive a turbine to generate electrical power. If compared to photovoltaic devices, which is a direct conversion process, a CSP plant has better conversion efficiency and the possibility of efficient storage of the thermal energy to be subsequently converted into electricity (Sioshansi and Denholm, 2010).

In a CSP plant, the solar collectors concentrate sunlight to heat a fluid (HTF - Heat Transfer Fluid) at a high temperature. The hot working fluid is used directly for different applications or for generating steam that drives a power conversion system for producing electricity (Camacho et al, 2012).

In solar power systems, the main source of energy cannot be manipulated as in other power generating processes. Moreover, a solar plant needs to deal with problems of seasonal and daily variations that are not found in other thermal power plants: the solar radiation depends on atmospheric conditions such as cloud cover, humidity, and air transparency (Camacho et al, 2012).
CSP plants are represented as a complex grid where each element has stationary and transient losses with changing dynamics, nonlinearities, and uncertainties. To avoid the use of complex mathematical models based on phenomenological equations that govern the dynamics of the system, an alternative is the use of system identification. According to the input and output data of a given dynamic system, the mathematical model can be represented by transfer functions, difference equations and/or state-space, for example.

In system identification, prediction error methods (PEM) and subspace identification are highlighted. Van Overschee and De Moor (1995), Viberg (2002) and Qin (2006) describe the advantages of subspace identification methods over traditional PEM, mainly applied to multivariable systems.

In terms of CSP plants, based on the mathematical model through the phenomenological equations for the Acurex plant at the Solar Platform of Almería, Spain, Camacho et al (2007a, 2007b) present a survey about the use of models based on system identification by PEM for application in the design of basic and advanced controllers. Alsharkawi and Rossiter $(2016,2017)$ apply PRBS signals generating output data, with such models identified by the subspace identification method N4SID (Numerical algorithms for 
Subspace State-Space System IDentification). These identified models were used with dual MPC (Model-based Predictive Control) and GS (Gain Scheduling) predictive control strategies, in order to improve the solar fields closedloop performance.

In this paper, a robust subspace identification algorithm for the combined deterministic-stochastic case proposed by Van Overschee and De Moor (1996) was used to represent a mathematical model which describes the dynamical behaviour of the ACUREX distributed solar collector fields, located in Almeria. In spite of having presented it in Van Overschee and De Moor (1996), the methodology has not received so many practical contributions for its use. The data set used in this paper is adequate for the combined deterministic-stochastic case, in which field inlet temperature, volumetric flow rate of the HTF, and solar radiation are treated as inputs and the field output temperature is treated as an output, representing a MISO (Multiple Input Single Output) case.

The paper is organized as follows: the CSP plant ACUREX in Almería, Spain is presented in section 2. The robust subspace identification algorithm used for obtain the mathematical model for ACUREX is introduced in section 3. In section 4 are presented the results, and in section 4 are given the conclusions.

\section{CSP PLANT ACUREX IN ALMERIA}

The CSP plant used to investigate the mathematical models by subspace identification was the ACUREX field prototype of the Plataforma Solar de Almería (PSA) located in the Tabernas Desert (Southern Spain). ACUREX field is a parabolic trough-based solar thermal power plant. The ACUREX field consists of 480 east-west aligned single axis tracking concentrating solar collectors organized in 10 parallel loops with a mirror area of $2672 \mathrm{~m}^{2}$. The loop is 172 $\mathrm{m}$ long formed by 4 modules of 12 collectors connected in series. The operation limits for HTF volumetric rate are 2,0 to $12,0 \times 10^{-3} \mathrm{~m}^{3} \mathrm{~s}^{-1}$. The maximum value is for avoiding the HTF decomposing, which happens when the temperature is up to $305^{\circ} \mathrm{C}$. For avoiding stress in the absorber pipe material, due to high HTF pressure in the pipe system, the difference between the inlet and outlet HTF temperatures must be less than $80^{\circ} \mathrm{C}$.

In Fig. 1 is shown a scheme of a solar collectors field, similar to the ACUREX field, and an overview of it can be found in Camacho et al (2012).

In terms of ACUREX field mathematical modelling, Camacho et al (2012) describe the dynamic behaviour by the set of energy balance partial differential equations (PDEs):

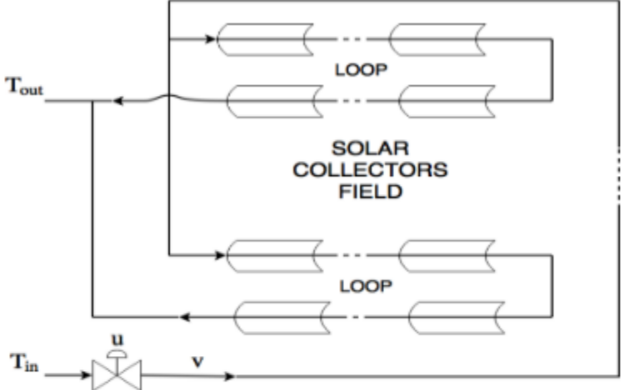

Fig. 1 - Solar collector field scheme. Field inlet temperature (Tin), volumetric flow rate of the HTF $(v)$, field output temperature (Tout), control signal (u) (Elias, 2018).

$$
\begin{aligned}
& \rho_{m} C_{m} A_{m} \frac{\partial T_{m}}{\partial t}=n_{0} G I-D_{0} \pi H_{l}\left(T_{m}-T_{a}\right)-D_{i} \pi H_{l}\left(T_{m}-T_{f}\right) \\
& \rho_{f} C_{f} A_{f} \frac{\partial T_{f}}{\partial t}+\rho_{f} C_{f} q \frac{\partial T_{f}}{\partial x}=D_{i} \pi H_{l}\left(T_{m}-T_{f}\right)
\end{aligned}
$$

where the sub-index $m$ refers to the metal of the receiver tube and $f$ to the HTF. In Table 1 there is a description of the parameters and variables and their SI units (Alsharkawi and Rossiter, 2016, 2017).

Table 1. Parameters and variables of the ACUREX PDEs.

\begin{tabular}{|l|l|l|}
\hline Symbol & Description & SI unit \\
\hline$\rho$ & Density & $\mathrm{Kg} / \mathrm{m}^{3}$ \\
\hline$C$ & Specific heat capacity & $\mathrm{J} / \mathrm{kg}^{0} \mathrm{C}$ \\
\hline$A$ & Cross-sectional area & $\mathrm{m}^{2}$ \\
\hline$T$ & Temperature & ${ }^{\circ} \mathrm{C}$ \\
\hline$t$ & Time & $\mathrm{S}$ \\
\hline$n_{0}$ & Mirror optical efficiency & - \\
\hline$G$ & Mirror optical efficiency & $\mathrm{m}$ \\
\hline$D_{0}$ & Outer diameter of the receiver tube & $\mathrm{m}$ \\
\hline$H_{l}$ & Global coefficient of thermal losses & $\mathrm{W} / \mathrm{m}^{0} \mathrm{C}$ \\
\hline$T_{a}$ & Ambient temperature & ${ }^{\circ} \mathrm{C}$ \\
\hline$D_{i}$ & Inner diameter of the receiver tube & $\mathrm{m}$ \\
\hline$H_{t}$ & Coefficient of metal-fluid heat transfer & $\mathrm{W} / \mathrm{m}^{20} \mathrm{C}$ \\
\hline$q$ & HTF volumetric flow rate & $\mathrm{m}^{3} / \mathrm{s}$ \\
\hline$x$ & Space & $\mathrm{m}$ \\
\hline
\end{tabular}

\section{ROBUST SUBSPACE IDENTIFICATION ALGORITHM}

In this section, the robust subspace identification algorithm for the deterministic-stochastic case is described. There are several forms of state-space representation. The innovation form is the one most commonly used in system identification, given as (Qin, 2006):

$$
\begin{aligned}
x_{k+1} & =A x_{k}+B u_{k}+K e_{k} \\
y_{k} & =C x_{k}+D u_{k}+e_{k}
\end{aligned}
$$

where $x_{k} \in \mathbb{R}^{n}$ (internal state vector), $y_{k} \in \mathbb{R}^{l}$ (output vector), $u_{k} \in \mathbb{R}^{m}$ (input vector), and $e_{k} \in \mathbb{R}^{m}$ is white noise. In these vectors, $n$ is the dimension of the state vector and represents the system order too, $m$ is the input dimension, and $l$ is the output dimension. In equations (2a)-(2b), $A \in \mathbb{R}^{n \times n}$ is the system matrix, $B \in \mathbb{R}^{n \times m}$ is the input 
matrix, $C \in \mathbb{R}^{l \times n}$ is the output matrix, $D \in \mathbb{R}^{l \times m}$ is the direct feedthrough matrix, and $K \in \mathbb{R}^{l \times m}$ is the Kalman gain.

The basic idea of subspace identification methods is to estimate the dynamical system order $n$, and the matrices $A, B, C, D$, and $K$ of the linear invariant-time (LIT) discrete state-space model (2a)-(2b), from the availability of the dynamical system acquired data set.

In representation (2a)-(2b), $e_{k}$ can be eliminated from the (2a) to yield a system description in one-step-ahead predictor form:

$$
\begin{aligned}
x_{k+1} & =\tilde{A} x_{k}+\tilde{B} u_{k}+K y_{k} \\
y_{k} & =C x_{k}+D u_{k}+e_{k}
\end{aligned}
$$

where $\tilde{A}=A-K C$ and $\tilde{B}=B-K D$. It is assumed the eigenvalues of $A-K C$ are strictly inside the unit circle.

After some algebraic manipulations, the subspace matrix equations are established for combined deterministicstochastic identification (Van Overschee and De Moor, 1996; Katayama, 2005):

$$
\begin{gathered}
Y_{p}=\Gamma_{i} X_{p}^{d}+H_{i}^{d} U_{p}+Y_{p}^{s} \\
Y_{f}=\Gamma_{i} X_{f}^{d}+H_{i}^{d} U_{f}+Y_{f}^{s} \\
X_{f}^{d}=A^{i} X_{p}^{d}+\Delta_{i}^{d} U_{p}
\end{gathered}
$$

with: $Y_{p}$ and $Y_{f}$, output vectors of the "past - $p$ " and the "future - $f$ ", respectively; $U_{p}$ and $U_{f}$, input vectors of "past" and "future", respectively. The index $d$ and $s$ indicate the use of subspace techniques for deterministic and stochastic systems, respectively. The matrices $\Gamma_{i}, \Delta_{i}^{d}$ and $H_{i}^{d}$ contained in (4a)-(4c) are referred as the extended observability matrix, the extended controllability matrix, and the Toeplitz matrix, respectively (Van Overschee and De Moor, 1996; Katayama, 2005). The extend observability $\left(\Gamma_{i}\right)$ and Toeplitz $\left(H_{i}^{d}\right)$ matrices, effectively used in the robust subspace identification algorithm, are written respectively as:

$$
\begin{gathered}
\Gamma_{i} \triangleq\left(\begin{array}{ccccc}
C & C A_{d} & C A_{d}{ }^{2} & \cdots & C A_{d}{ }^{i-1}
\end{array}\right)^{T} \in \mathbb{R}^{l i \times n} \\
H_{i}^{d}=\left[\begin{array}{ccccc}
D & 0 & 0 & \cdots & 0 \\
C B & D & 0 & \cdots & 0 \\
C A B & C B & D & \cdots & 0 \\
\cdots & \cdots & \cdots & \cdots & \cdots \\
C A^{i-2} B & C A^{i-3} B & C A^{i-4} B & \cdots & D
\end{array}\right] \in \mathbb{R}^{l i \times m i}
\end{gathered}
$$

The input $\left(U_{p}\right.$ and $\left.U_{f}\right)$ and output $\left(Y_{p}\right.$ and $\left.Y_{f}\right)$ Hankel matrices are formed through input and output data set. Hankel's matrices of past " $p$ " and future $f$ "" input are defined, respectively (Van Overschee and De Moor, 1996):

$$
\begin{aligned}
U_{p} \triangleq U_{0 \mid i-1} & \triangleq\left(\begin{array}{cccc}
u_{0} & u_{1} & \ldots & u_{j-1} \\
u_{1} & u_{2} & \ldots & u_{j} \\
\vdots & \vdots & \ddots & \vdots \\
u_{i-1} & u_{N} & \ldots & u_{i+j-2}
\end{array}\right) \\
U_{f} \triangleq U_{i \mid 2 i-1} \triangleq & \left(\begin{array}{cccc}
u_{i} & u_{i+1} & \ldots & u_{i+j-1} \\
u_{i+1} & u_{i+2} & \ldots & u_{i+j} \\
\vdots & \vdots & \ddots & \vdots \\
u_{2 i-1} & u_{2 i} & \ldots & u_{2 i+j-2}
\end{array}\right)
\end{aligned}
$$

where $U_{p}, U_{f} \in \mathbb{R}^{m i \times j}$ with the subscript $k_{1} \mid k_{2}$ indicating the first column of the subspace matrix/vector begins at the discrete time $k_{1}$ and ends at $k_{2}$. The index $j$ (number of columns) is typically equal to $s-2 i+1$, implying that all given data samples are used. The output block Hankel matrices, $Y_{p}, Y_{f} \in \mathbb{R}^{l i \times j}$ are defined in a similar way to the matrices (6a) and (6b). The matrices $Y_{f}^{-}, U_{f}^{-}$on the other hand, are defined by shifting the border between past and future one block row down.

In the subspace identification literature, the notation of (7) is often used (Van Overschee and De Moor, 1996):

$$
W_{p}=\left(\begin{array}{c}
Y_{p} \\
U_{p}
\end{array}\right)
$$

where $W_{p} \in \mathbb{R}^{(m i \times l i) \times j}$ is the matrix of past input and output data.

\subsection{The Algorithm}

The algorithm is started by calculating the oblique $\left(\mathcal{O}_{i}\right)$ and orthogonal $\left(Z_{i}\right)$ projections, respectively by:

$$
\begin{gathered}
\mathcal{O}_{i}=Y_{f} / U_{f} W_{p}, \quad Z_{i}=Y_{f} /\left[\begin{array}{l}
W_{p} \\
U_{f}
\end{array}\right], \\
Z_{i+1}=Y_{f}^{-} /\left[\begin{array}{c}
W_{p}^{+} \\
U_{f}^{-}
\end{array}\right]
\end{gathered}
$$

In (7), the projection $Z_{i}$ could be considered an optimal prediction of the future output $Y_{f}$, given the past input and output data $W_{p}$ and the future input data $U_{f}$. The interpretation for $Z_{i+1}$ is that the offset projection of the edge between past and future one down (Van Overschee and De Moor, 1996). It can be noticed the oblique and orthogonal projections do not depend on the calculations of the statespace matrices but only the input and output data.

The SVD (Singular Value Decomposition) calculation is done by the weighted oblique projection:

$$
W_{1} \mathcal{O}_{i} W_{2}=U S V^{T}
$$

with $W_{1}$ and $W_{2}$ weighting matrices chosen as $I$ (identity matrix) and $\Pi_{U_{f}^{\perp}}$, respectively. $\Pi_{U_{f}^{\perp}}$ denotes the operator that projects the row space of a matrix onto the row space of $U_{f}^{\perp}$ and $U_{f}^{\perp}$ denotes the subspace perpendicular to the row space of $U_{f}$ (Van Overschee and De Moor, 1995).

The system order is determined by inspecting the singular values in $S$ and partition the SVD accordingly to obtain $U_{1}$ and $S_{1}$. The matrices $\Gamma_{i}$ and $\Gamma_{i-1}$ are determined as:

$$
\Gamma_{i}=U_{1} S_{1}^{1 / 2}, \Gamma_{i-1}=\underline{\Gamma_{i}}
$$

where $\underline{\Gamma_{i}}$ denotes $\Gamma_{i}$ without the last $l$ rows.

To calculate the matrices $A$ (with stability guarantee) and $C$ can be extracted from $\Gamma_{i}$. The stable matrix can be calculated by following procedure indicated in (Van Overschee and De Moor, 1996): 


$$
A=\Gamma_{i}^{\dagger} \cdot\left[\begin{array}{c}
\overline{\Gamma_{l}} \\
0
\end{array}\right]
$$

where 0 represent $l$ rows of zeros, and $\overline{\Gamma_{l}}$ denotes $\Gamma_{i}$ without the first $l$ rows. The matrix $C$ can be determined from the first $l$ rows of $\Gamma_{i} . \Gamma_{i}^{\dagger}$ denotes the Moore-Penrose inverse of $\Gamma_{i}$.

From $A$ and $C$ one must recompute $\Gamma_{i}$ and $\Gamma_{\mathrm{i}-1}$ since original $\Gamma_{i}$ and $\Gamma_{i-1}$ determined from (10) are only approximations of the exact $\Gamma_{i}$ and $\Gamma_{i-1}$.

The $B$ and $D$ matrices accuracy tends to be poor in case of badly conditioned input Hankel matrices. As $A, C, \Gamma_{\mathrm{i}}$, and $\Gamma_{i-1}$ are known, $B$ and $D$ are computed as:

$$
B, D=\arg { }_{B, D}^{\min }\|\mid \underbrace{\left[\begin{array}{c}
\Gamma_{i}^{\dagger} Z_{i+1} \\
Y_{i \mid i}
\end{array}\right]-\left[\begin{array}{l}
A \\
C
\end{array}\right] \cdot \Gamma_{i}^{\dagger} \cdot Z_{\mathrm{i}}}_{\text {known }}-\kappa(B, D) \cdot \underbrace{U_{f}}_{\text {known }}\|_{F}^{2}
$$

with $\|\cdot\|_{F}^{2}$ refers to the Frobenius norm squared, and $\kappa(B, D)$ refers to the linear matrix function defined by

$$
\kappa \triangleq\left[\begin{array}{c}
\left(B \mid \Gamma_{i-1}^{\dagger} \cdot H_{i-1}^{d}\right)-A \cdot \Gamma_{i}^{\dagger} \cdot H_{i}^{d} \\
(D \mid 0)-C \cdot \Gamma_{i}^{\dagger} \cdot H_{i}^{d}
\end{array}\right]
$$

Since $\kappa(B, D)$ is linear in $B$ and $D$, the overall optimization problem is convex, and thus has a unique minimum. The problem can be solved by either using a optimization algorithm, or by rewriting the function between the norm signs in (12) as an explicit linear combination of $B$ and $D$ and solving this set of equation in a least squares sense, this second way is used in this paper (Van Overschee and De Moor, 1996).

Finally, the covariance matrices $Q, R$ and $S$ can be approximated from the residuals $\rho_{w}$ and $\rho_{v}$ :

$$
\left[\begin{array}{cc}
Q & S \\
S^{T} & R
\end{array}\right]=E\left(\left[\begin{array}{c}
\rho_{w} \\
\rho_{v}
\end{array}\right] \cdot\left[\begin{array}{ll}
\rho_{w}^{T} & \rho_{v}^{T}
\end{array}\right]\right)
$$

with the covariance matrices and residuals are positive definite. These covariance matrices are used for calculation of Kalman gain in the forward innovation model by solving the Riccati equation in (15):

$$
K=\left(G-A P C^{T}\right)\left(\Lambda_{0}-C P C^{T}\right)^{-1}
$$

where

$$
\begin{gathered}
P=\left(A P A^{T}\right)+\left(G-A P C^{T}\right)\left(\Lambda_{0}-C P C^{T}\right)^{-1}\left(G-A P C^{T}\right)^{T} \\
E\left[x_{k}^{S}\left(x_{k}^{S}\right)^{T}\right]=\Sigma^{S}=A \Sigma^{S} A^{T}+Q \\
E\left[y_{k} y_{k}^{T}\right]=\Lambda_{0}=C \Sigma^{S} C^{T}+R \\
E\left[x_{k+1}^{S} y_{k}^{T}\right]=G=A \Sigma^{s} C^{T}+S
\end{gathered}
$$

with $P$ as the forward state covariance matrix, $\Sigma^{s}$ is the state covariance matrix, and $\Lambda_{0}, G$ are the output covariance matrices also considered as Markov parameters of the deterministic linear time invariant system, as described in (Van Overschee and De Moor, 1996).

In addition, a detailed scheme of the robust combined deterministic-stochastic identification algorithm is illustrated in Fig. 2.

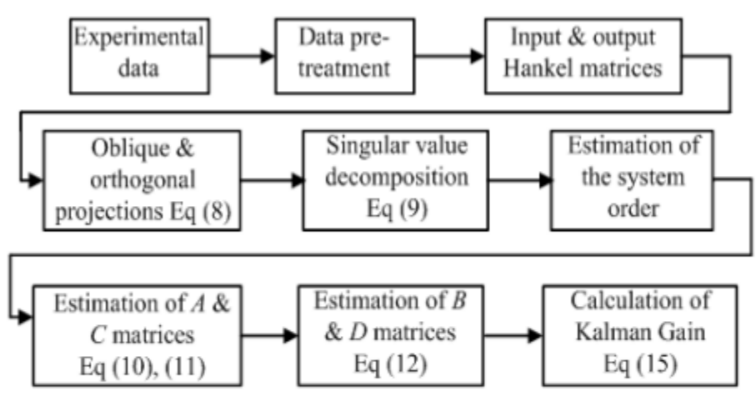

Fig. 2 - Scheme of the robust combined deterministicstochastic identification algorithm.

\section{RESULTS AND VALIDATION}

The data set used in this paper was obtained from the Acurex field, installed in the Plataforma Solar de Almería (PSA) located in the Tabernas Desert (Southern Spain). The Acurex field input and output data set were acquired in February 1997, with $11 \mathrm{~ms}$ of interval, where the inputs are the field inlet temperature $\left({ }^{\circ} \mathrm{C}\right)$, volumetric flow rate of the HTF $(\mathrm{l} / \mathrm{s})$, and solar radiation $\left(\mathrm{W} / \mathrm{m}^{2}\right)$, and the output is the field output temperature $\left({ }^{\circ} \mathrm{C}\right)$, with about 410 samples in each. In the data pre-treatment stage, these are normalized, outliers and offset values are removed, a data resampling by a factor of 2 is applied, without filter usage. The normalized data set is shown in Fig. 3.
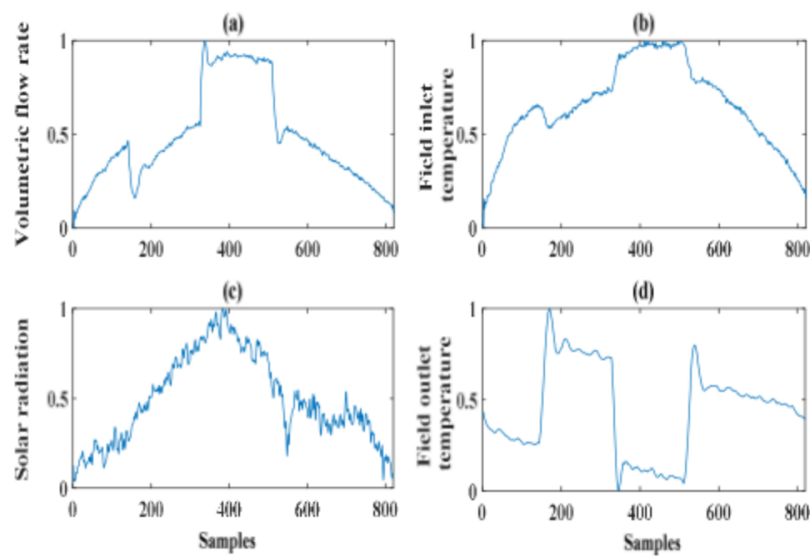

Fig. 3 - The normalized data set of the ACUREX field identification and validation, after the data pre-processing step. (a) Volumetric flow rate, (b) field inlet temperature, (c) solar radiation and (d) field output temperature.

The SVD calculated by (9) - (10) are used to investigate the order of the dynamical system model. By inspecting the gap between the high values in Fig. 4, order 3 can be chosen. The Mean Relative Square Error (MRSE) index is performed to determine whether the immediately higher order 4 would be better than third order to represent the dynamical behavior of the solar field outlet temperature. The MRSE index was calculated for the robust combined deterministic-stochastic and MOESP (Multivariable Output Error State sPace) identification algorithms.

MRSE (Mean Relative Square Error) index is calculated as: 


$$
\text { MRSE }=\left[1-\left(\frac{1}{l} \sum_{i=1}^{l} \sqrt{\frac{\sum_{k=1}^{N}\left(\left(y_{k}\right)_{i}-\left(\hat{y}_{k}\right)_{i}\right)^{2}}{\sum_{k=1}^{N}\left(\left(y_{k}\right)_{i}\right)^{2}}}\right)\right] \times 100 \%
$$

where $l$ is the number of outputs of the dynamical system, $y_{k}$ is the experimental output data used for the validation, and $\hat{y}_{k}$ is the estimated output data. The MRSE index varies between 0 (bad fit) to $100 \%$ (perfect fit).

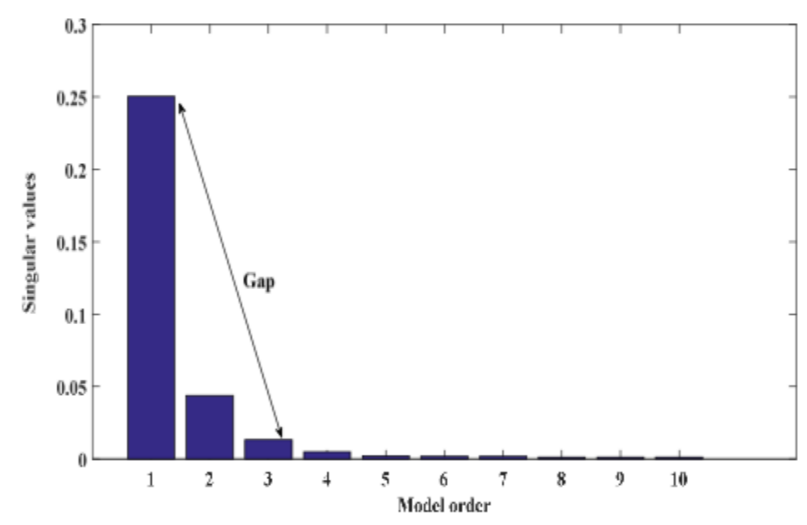

Fig. 4 - SVD values using the robust combined deterministicstochastic subspace identification algorithm.

The MRSE values index for one-step-ahead prediction of the dynamical system output (normalized field outlet temperature) for order 3 and order 4 are close and by parsimony analysis, the chosen model is of third order. The results in Table 2 are similar to those obtained by Alsharkwai and Rossiter (2017), who chose a 4th order model for the design of the developed controllers. In this paper, a 3rd order model is indicated so that model-based controller designs can be developed in the future.

Still with the data in Table 2, it can be seen that the MRSE index for the one-step-ahead prediction has a better percentage. This is explained by the inclusion of the Kalman gain $(K)$ in the output predictions considering the existence of disturbances in the system input (solar radiation). In Table, The computation time recorded of each identification algorithm indicates the robust combined deterministicstochastic is 4 times faster than MOESP algorithm, approximately (Intel Core i5 with 8 GB of RAM).

Table 2. MRSE index with variations in the order systems.

\begin{tabular}{|c|c|c|c|}
\hline Order & Method & $\begin{array}{c}\text { MRSE index } \\
\text { (\%) }\end{array}$ & $\begin{array}{c}\text { Comput. } \\
\text { time (s) }\end{array}$ \\
\hline \multirow{2}{*}{3} & $\begin{array}{c}\text { MOESP - deterministic } \\
\text { case }\end{array}$ & 92.34 & 0.37 \\
\cline { 2 - 4 } & $\begin{array}{c}\text { Robust combined } \\
\text { deterministic-stochastic }\end{array}$ & 95.04 & 0.13 \\
\hline \multirow{2}{*}{4} & $\begin{array}{c}\text { MOESP - deterministic } \\
\text { case }\end{array}$ & 94.35 & 0.45 \\
\cline { 2 - 4 } & $\begin{array}{c}\text { Robust combined } \\
\text { deterministic-stochastic }\end{array}$ & 96.19 & 0.12 \\
\hline
\end{tabular}

The data set used has 413 samples for identification, corresponding to half of the data, and the others for validation. In Fig. 6, the ACUREX plant field outlet temperature normalized graphs are shown with data used in the state-space model estimation step. The experimental data are compared with the data used in the free simulation estimation (2a-2b), one-step-ahead prediction (3a-3b) both using the robust combined deterministic-stochastic algorithm and the free simulation prediction for MOESP. From the comparison with plant output, the effectiveness of robust combined deterministic-stochastic algorithm is clearly demonstrated. The identified system matrices and Kalman gain are given in the Appendix.

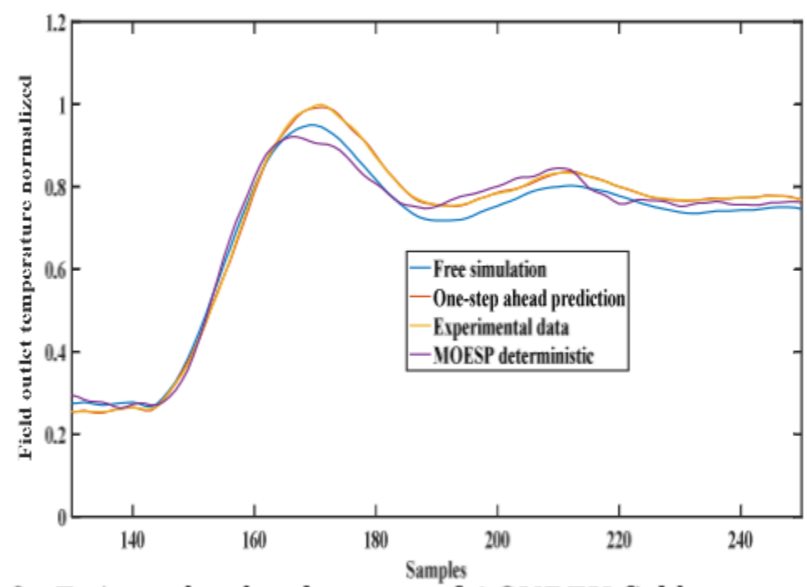

Fig. 6 - Estimated and real outputs of ACUREX field.

In the validation step, the output data is compared to the onestep-ahead prediction. From the results shows in Fig. 7, it can be observed that the employed algorithm was successful, with RMSE index of $98.56 \%$. These results suggest that the estimated LIT discrete state-space model is satisfactory, showing the good properties of the robust combined deterministic-stochastic subspace identification algorithm.

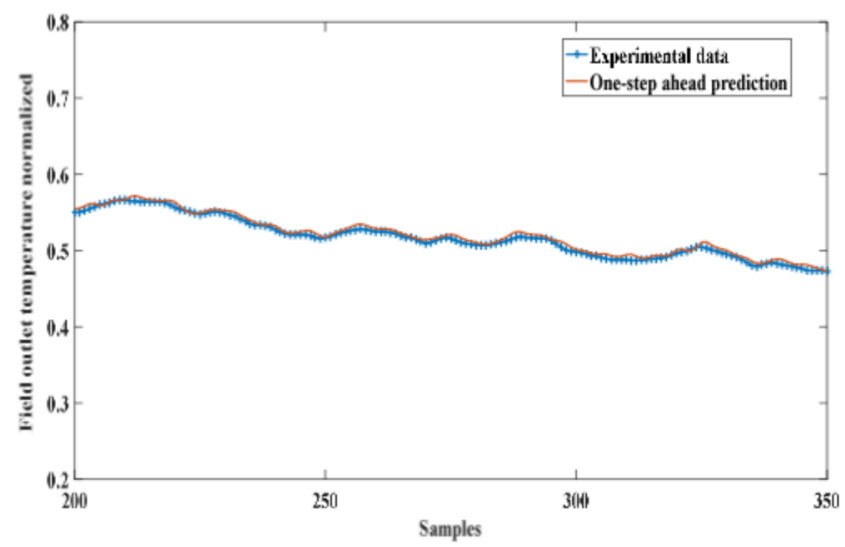

Fig. 7 - Validation based on the robust combined deterministic-stochastic identification algorithm.

\section{CONCLUSIONS}

In this paper, an offline subspace identification algorithm was used to identify discrete LTI state-space model that represents the dynamic behavior of the ACUREX field in Almería, Spain. The technique that combines the stochastic and deterministic parts has an advantage over techniques that are based only on the deterministic part, such as MOESP, including a shorter computational time. 
Moreover, the parameters of the phenomenological equation models do not need to be estimated, calculated or measured, since identification techniques use experimental data from the dynamical system.

In future works, the state-space model will be used in modelbased controllers, and the connection of the ACUREX solar field in the context of smart grids to optimize the production of the active power.

\section{ACKNOWLEDGMENT}

The authors thank CAPES (Coordination for the Improvement of Higher Education Personnel), during the postdoctoral stage (A. G. C. J.) at the Federal University of Santa Catarina (UFSC), CNPq (National Council for Scientific and Technological Development) for projects 401126/2014-5, 303702/2011-7 and 305785/2015 - 0, Federal Institute of Paraiba (IFPB) and Plataforma Solar de Almería (PSA) for the data available.

\section{REFERENCES}

Alsharkawi, A., and Rossiter, J. A. (2016). Dual mode MPC for a concentrated solar thermal power plant. $11^{\text {th }}$ IFAC Symposium on Dynamics and Control of Process Systems, including Biosystems (DYCOPS'16), Trondheim (Norway), pp. 260-265.

Alsharkawi, A., and Rossiter, J. A. (2017). Towards an improved gain scheduling predictive control strategy for a solar thermal power plant. IEC Control Theory \& Applications, vol. 11, n. 12, pp. 1938-1947.

Camacho, E. F. et al. (2007a). A survey on control schemes for distributed solar collector fields. Part I: modeling and basics control approaches. Solar Energy, vol. 81, pp. 1240-1251.

Camacho, E. F. et al. (2007b). A survey on control schemes for distributed solar collector fields. Part II: advanced control approaches. Solar Energy, vol. 81, pp. 12521272.

Camacho, E. F. et al. (2012). Control of solar energy systems. Springer Verlag.

Elias, T. A. (2018). Hybrid model predictive control for solar fields. Master's Thesis. Universidade Federal de Santa Catarina (Brazil).

Katayama, T. (2005). Subspace methods for system identification: a realization approach, Springer.

Qin S. J. (2006). An overview of subspace identification. Computers and Chemical Engineering, vol. 30, n. 10-12, pp. 1502-1513.

Sioshansi, R., and Denholm, P. (2010). The value of concentrating solar power and thermal energy storage. IEEE Transactions on Sustainable Energy, vol. 1, n. 3, pp. 173-183.

Van Overschee, P., and De Moor, B. (1995). A unifying theorem for three subspace system identification algorithms. Automatica, vol. 31, n. 12, pp. 1853-1864.

Van Overschee, P., and De Moor, B. (1996). Subspace identification for linear system: theory, implementation, applications, Doordrecht (Netherlands): Kluwer.

Viberg, V. (2002). Subspace-based state-space system identification. Circuits Systems Signal Processing, vol. 21, n. 1, pp. 23-37.
APPENDIX

\begin{tabular}{|c|c|c|c|c|c|c|}
\hline Matrix & \multicolumn{3}{|c|}{ MOESP } & \multicolumn{3}{|c|}{$\begin{array}{c}\text { Robust combined } \\
\text { deterministic-stochastic }\end{array}$} \\
\hline$A$ & {$\left[\begin{array}{c}0.936 \\
0.003 \\
-0.001\end{array}\right.$} & $\begin{array}{c}-0.632 \\
0.823 \\
-0.026\end{array}$ & $\left.\begin{array}{c}-0.389 \\
1.537 \\
0.995\end{array}\right]$ & {$\left[\begin{array}{c}0.935 \\
-0.013 \\
-0.036\end{array}\right.$} & $\begin{array}{c}-0.073 \\
0.958 \\
-0.049\end{array}$ & $\left.\begin{array}{l}0.033 \\
0.190 \\
0.901\end{array}\right]$ \\
\hline$B$ & {$\left[\begin{array}{c}0.225 \\
-0.201 \\
-0.002\end{array}\right.$} & $\begin{array}{l}-0.604 \\
-0.188 \\
-0.203\end{array}$ & $\left.\begin{array}{l}-0.027 \\
-0.080 \\
-0.003\end{array}\right]$ & {$\left[\begin{array}{c}1.101 \\
-0.467 \\
0.852\end{array}\right.$} & $\begin{array}{c}-0.382 \\
0.542 \\
-0.281\end{array}$ & $\left.\begin{array}{c}-0.291 \\
0.222 \\
-0.248\end{array}\right]$ \\
\hline C & {$[-0.504$} & -0.657 & $0.467]$ & {$[-0.186$} & -0.077 & $0.052]$ \\
\hline$D$ & \multicolumn{3}{|c|}{$\left[\begin{array}{lll}0 & 0 & 0\end{array}\right]$} & {$[0.087$} & 0.005 & $0.000]$ \\
\hline K & \multicolumn{3}{|c|}{$\left[\begin{array}{l}0 \\
0 \\
0\end{array}\right]$} & \multicolumn{3}{|c|}{$\left[\begin{array}{c}-8.683 \\
9.931 \\
-3.643\end{array}\right]$} \\
\hline
\end{tabular}

